\title{
A Study on the Factors Influencing the Cross-Cultural Adaptation of Chinese Students of Different Academic Level-Taking Guangdong University of Foreign Studies as an Example
}

\author{
Risheng Zhong, Di Wang, Yuanyuan Chen*, Yuyang Cao \\ Guangdong University of Foreign Studies, Guangzhou, China \\ Email: ^201110068@oamail.gdufs.edu.cn
}

How to cite this paper: Zhong, R. S. Wang, D., Chen, Y. Y., \& Cao, Y. Y. (2020). A Study on the Factors Influencing the Cross-Cultural Adaptation of Chinese Students of Different Academic Level-Taking Guangdong University of Foreign Studies as an Example. Creative Education, 11, 25592569.

https://doi.org/10.4236/ce.2020.1112188

Received: November 11, 2020

Accepted: December 7, 2020

Published: December 10, 2020

Copyright $\odot 2020$ by author(s) and Scientific Research Publishing Inc. This work is licensed under the Creative Commons Attribution International License (CC BY 4.0).

http://creativecommons.org/licenses/by/4.0/

\begin{abstract}
This study uses a self-compiled and formatted questionnaire to test the differences of cross-cultural adaptation of Chinese students with different initial academic levels, and explore the correlation between students' academic level and various factors that affect cross-cultural adaptation. This study takes 245 students from Guangdong University of Foreign Studies who went to study in the UK in 2018 as a sample. The study found that the initial academic level was significantly related to the "interpersonal relationship", "environmental factors" and "psychological adaptation" of students' cross-cultural adaptation, and has no significant correlation with "academic situation".
\end{abstract}

\section{Keywords}

Different Initial Academic Levels, Chinese Students Abroad, Cross-Cultural Adaptation, Relevance

\section{Introduction}

With the increasing number of Chinese students going to the UK in recent years, the problem of cross-cultural adaptability of international students has become increasingly prominent, which has also attracted widespread attention from scholars at home and abroad. On one hand, due to differences in language proficiency and social culture, it is difficult for international students to fully integrate into the local cultural environment. On the other hand, international students 
and their families are under greater economic pressure. Therefore, compared with local students in the UK, some international students experience poor physical conditions during their study abroad, showing mental symptoms such as paranoia, anxiety, and depression (Jiang, 2000).

Researches confirm that Chinese international students have difficulties in crosscultural adaptation abroad. After international students start studying abroad, they are faced with a new teaching system and form. They have to adapt to unfamiliar foreign cultures, establish a new circle of friends, and deal with all aspects of life alone, which means huge pressure and challenges to them.

Solving the cultural adaptability of Chinese students studying abroad is of great significance not only to the students themselves and their families, but also to the study of cross-border higher education. At present, in the research of crosscultural adaptability, the research focus of domestic research scholars mainly focuses on the management of international students in China and the adaptability under the Chinese cultural background. There are few cross-cultural adaptability studies for Chinese students studying abroad. The study on the cross-cultural adaptability of Chinese students studying abroad in articulation program is still blank.

An important form of studying abroad in China is the articulation program, which refers to education and teaching activities that Chinese higher education institutions and foreign higher education institutions cooperate in disciplines, majors, and courses without setting up educational institutions. Students study in a Chinese university for a period of time (usually one or two years), and after reaching the corresponding academic standards, they will go to the UK to complete the remaining two years of undergraduate courses and finally obtain a British university degree. This is currently the main form of Sino-foreign cooperation in running schools in Chinese universities, and has shown a trend of rapid development in recent years (Zhan, 2017).

The overseas study and life of the students of the articulation program is not only novel and mysterious, but also stress and discomfort. It is a journey of severe reality challenging romantic dreams. Difficulties in language, changes in learning styles, academic pressures, climate and dietary discomforts, changes in communication styles, and various difficulties and problems caused by cultural differences, as well as prejudice and discrimination encountered or perceived due to cultural imbalance between China and foreign countries, will to a large extent affect students' learning and living conditions in the new cultural environment (Huang, 1994). Their acceptance and adaptation to the new culture of the country where they study abroad and their awareness of traditional Chinese culture have a very important impact on their academic achievements, mental health and personal development. In the articulation program of Guangdong University of Foreign Studies (GDUFS), the various British program universities rank differently, for example, Lancaster University, which ranks seventh in the United Kingdom, and the University of Central Lancashire, which is in the middle 
reaches. Different project schools have different entrance requirements for students, which means that the starting level of students is different in different project schools. After completing the two-year study at GDUFS, students need to go to the UK to continue their studies for two years to obtain a bachelor's degree. In the two years in the UK, especially when they first entered the UK, due to the huge differences between China and the UK in education models and living environments, students will encounter various difficulties in cross-cultural adaptation when studying in the UK. The level of cross-cultural adaptation has an important influence on whether students can successfully complete their studies (Yang, 2019).

\section{Research Background}

In China, the research on the cross-cultural adaptation of international students started relatively late. Most of the research objects are mainly for international students, business professionals, foreign teachers, and TCSL teachers abroad (Fang, 2010).

In his thesis An Analysis of Overseas Chinese Students' Cultural and Solution-A Case Study on Oklahoma State University, LI Xianzhi conducted a questionnaire survey and interviews with 407 Chinese students studying in universities in the US, which analyze the factors affecting cross-cultural adaptation from both internal and external perspectives, and propose corresponding countermeasures from the two levels of the improvement of students' personal adaptability (internal) and the construction of social support networks (external) (Li, 2011). WANG Yuan pointed out in An Analysis of Chinese Students Studying Abroad in the United States and Their Cultural Adaptability that Chinese students pay more attention to language and academics when preparing for studying abroad, but ignore the pre-understanding of the culture and values of the country where they study, thus causing barriers to cross-cultural adaptation (Wang, 2012). Tan Yu's doctoral dissertation Research on the Cross-cultural Adaptation of Students in Sino-foreign Cooperation in Running Schools in Universities mainly used questionnaires, observations, interviews and other methods to investigate the current cross-cultural adaptability of students in Sino-foreign cooperative education in universities. The author combines the relevant theories and models of cross-cultural adaptation to evaluate students' cross-cultural adaptation status and influencing factors. Through qualitative analysis, the author further constructs the corresponding theoretical framework of cross-cultural adaptation (Tan, 2013). In the paper On Self-Concept and Cultural Identity Reconstruction Issues of Chinese International Students, TAN Yu explores the self-concept and cultural identity reconstruction of Chinese international students in the process of crosscultural interaction through qualitative research methods. It aims to have a more comprehensive and in-depth understanding of the cross-cultural adaptation status of Chinese students and its in-depth influencing factors, and provide an effective reference for how to correctly cultivate and improve students' cultural self-con- 
fidence, cultural awareness, cultural selection and discrimination and other crosscultural capabilities (Tan, 2014). In The Condition of Inter-cultural Adaption in UK among the Chinese Postgraduate Students, Wang Kunchen explores the crosscultural adaptation status of foreign students in the UK. Research has found that international students face great difficulties in social integration, which emphasizes the necessity and importance of students' own "cultural awareness" (Wang, 2013a). In her thesis Investigation of Chinese Young Abroad Students on Crosscultural Adaption-A case Study of Chinese Young Abroad Students in America from Xintong Education Agent, Wang Li analyzes the influencing factors of crosscultural adaptation from four aspects of ability, education system, values, and time of studying abroad, based on which puts forward suggestions (Wang, 2013b).

Through previous research of this study, it can be seen that Chinese students' cross-cultural adaptation is mainly determined by four influencing factors: academic performance, interpersonal relationships, environmental factors and psychological adaptation.

\section{Research Synopsis}

In China, teachers and parents of students generally believe that students with good academic performance will have better self-management skills and other outstanding qualities. For a long time, the issue of Chinese students' cross-cultural adaptation has not been paid attention to. Questions such as what influence factors constitute cross-cultural adaptation and what variables will interact with the level of cross-cultural adaptation have not been well answered. It is generally believed that students who study well are also excellent in other areas, so they will be more likely to complete cross-cultural adaptation. This is an inherent impression that everyone has always had, but it is rarely tested by experimental means.

In this study, the author assumes that the different academic levels of students may have an impact on the factors affecting cross-cultural adaptation. In other words, students with high academic levels will have more ease in cross-cultural adaptation, while students with relatively weak academic levels will encounter more difficulties in cross-cultural adaptation and take longer to complete crosscultural adaptation.

In order to test the correlation between the cross-cultural adaptability of the students of the articulation program and the academic level of the students, this study uses the self-compiled questionnaire "Questionnaire on the cross-cultural adaptability of students in the UK class of the articulation program" to survey the cultural adaptability and academic level of 245 students of the articulation program of Guangdong University of Foreign Studies to study in the UK in 2018.

\section{Research Hypothesis}

This research assumes that the cultural adaptability of overseas study training program students is positively related to their academic level. The experiments 
interviewed 161 students from Lancaster University, the University of Leicester, Coventry University, the University of Central Lancashire, and the University of Portsmouth in the aforementioned "Study on the Factors Affecting the Crosscultural Adaptability of Students in the UK Class of the Articulation Program". Among them, students belonging to Lancaster University and University of Leicester in the United Kingdom are in the high academic level group, because Lancaster University ranks 131st in 2019 QS world rankings and ranks 7th in CUG, ranks 9th in the UK in the Guardian rankings while and University of Leicester ranks 223rd in 2019 QS World Rankings, ranks 167th in Times World Rankings and ranks 44th in CUG Rankings. These two are the top universities in the UK, and the students' academic level and personal comprehensive ability are both strong. Those who entered Coventry University, which ranks 13th in the Guardian in 2019 and 53rd in the UK by CUG, University of Portsmouth, which ranked 25 in the Guardian in 2019, 53rd in the UK by CUG, University of Central Lancashire, which ranks 76th in the Guardian rankings 2019 ranked 76th in the UK and ranks 75th in the UK by CUG are in the medium academic level group, because these 3 universities are located in the medium level of British universities. The academic level and comprehensive ability of those who entered these three universities are inferior to those of the previous two universities.

\section{Research Method}

Self-edited and formatted questionnaire "Questionnaire on Cross-cultural Adaptability of Students in the Articulation Program" includes four factors such as "academic situation", "interpersonal relationship", "environmental factors" and "psychological adaptation". It is composed of 32 questions and uses Likert's five-point scoring system, which requires that $1,2,3,4$, and 5 points are to reflect the situation from "disagree very much" to "agree very much". In order to avoid the social expectation effect and meet the need for polygraph detection, some reverse questions are set up. The reverse questions adopt the method of reverse scoring, that is, 5 points, 4 points, 3 points, 2 points, and 1 point reflects "disagree very much" to "agree very much".

\section{Formal Measurement}

The questionnaire is supplied with the instructions and the questions are randomly arranged and it also informs the respondents of the significance of the investigation and privacy protection measures. The author went to the University of Lancaster, University of Leicester, University of Coventry, University of Central Lancashire, University of Portsmouth, University of Westminster and University of Bedfordshire to collect questionnaires on the spot. The questionnaires were filled out anonymously and received on the spot. In total 245 questionnaires were sent out, 210 valid questionnaires were returned, and the effective response rate was $85.7 \%$. In this study, 58 samples of students from the University of Lancaster and the University of Leicester in the United Kingdom 
were named as the "high academic level group"; The 103 samples of students from Coventry University, University of Central Lancashire, University of Portsmouth were named "medium academic level group".

Following the principles of uniformity, standardization, concealment, single blindness, etc., when inputting data, the subject content is hidden. The author is responsible for data input and check the data input situation again after inputting. The author uses SPSS 22.0 to import raw data from excel, and compares the cultural adaptability level of the high academic level group and the medium academic level group, performs $t$ test, and if $\mathrm{P}$ is not more than 0.05 , it indicates that the difference is statistically significant. In the average score of academic situation dimension, the difference between high academic level group (3.86 \pm $0.73)$ and medium academic level group $(3.67 \pm 0.84)$ was not significant $(\mathrm{t}=$ $1.41, p=0.16>0.05)$. In the average score of interpersonal relationship, high academic level group $(3.89 \pm 0.87)$ and medium academic level group (3.48 \pm $1.11)$ are significantly different $(t=2.38, p=0.02<0.05)$, and the interpersonal scores of high academic level group are higher than those of medium academic level group. On the average score of environmental factors, high academic level group (3.48 \pm 0.78$)$ and medium academic level group (3.16 \pm 0.67$)$ are significantly different $(\mathrm{t}=2.67, p=0.01<0.05)$, and high academic level group have higher environmental dimension scores than medium academic level group. In the psychological dimension, there is a significant difference between high academic level group $(3.72 \pm 0.90)$ and medium academic level group (4.09 \pm 0.75$)$ $(\mathrm{t}=-2.67, p=0.01<0.05)$, and the environmental dimension scores of high academic level group are lower than those of medium academic level group. In the total score dimension, the difference between high academic level group $(115.71 \pm 17.17)$ and medium academic level group $(111.79 \pm 16.11)$ is not significant $(\mathrm{t}=1.34, p=0.17>0.05)$.

The scores of the four dimensions of cultural adaptability for the high-level and medium-level groups are shown in Table 1.

The comparison of scores on various dimensions of different academic level groups is shown in Table 2. The scores the high academic level group in the two dimensions of interpersonal relationship and environmental factors are higher than those of the medium academic level group, and there are differences $(p<$ 0.1 ). The scores of the high academic level group in the psychological dimension are obviously lower than the medium academic level group $(p<0.05)$, and the two groups have no significant difference in the scores of academic dimensions $(p>0.05)$. The total score of high academic level group is higher than the medium academic level group, and there is a significant difference $(p<0.05)$.

\section{Result Analysis}

The results of the study show that the scores of students in the high academic level group on the "academic situation" dimension are not significantly different from those in the medium academic level group; the scores of students in the high academic level group score on the two dimensions of "interpersonal relationship" 
Table 1. Cultural adaptability scores of different academic levels.

\begin{tabular}{cccccc}
\hline & Groups & Samples & Average score & Standard deviation & Standard error of the mean \\
\hline \multirow{2}{*}{ Academic situation } & high-level & 58 & 3.8602 & 0.73484 & 0.09649 \\
& medium-level & 103 & 3.617 & 0.83912 & 0.08268 \\
Interpersonal relationship & high-level & 58 & 3.8879 & 0.86371 & 0.11341 \\
& medium-level & 103 & 3.6036 & 0.97772 & 0.09634 \\
Environmental factors & high-level & 58 & 3.4828 & 0.77885 & 0.10227 \\
& medium-level & 103 & 3.2184 & 0.60221 & 0.05934 \\
Psychological adaptation & high-level & 58 & 3.7177 & 0.90217 & 0.11846 \\
& medium-level & 103 & 4.0692 & 0.71545 & 0.0705 \\
Total score & high-level & 58 & 115.6724 & 17.12635 & 2.2488 \\
\hline
\end{tabular}

Table 2. Comparison of scores in various dimensions of different academic level groups.

\begin{tabular}{|c|c|c|c|c|c|c|c|c|c|c|}
\hline & & \multicolumn{4}{|c|}{ Levine Variance Equivalence Test } & \multicolumn{5}{|c|}{ Mean equivalence $t$ test } \\
\hline & & \multirow{2}{*}{$\mathbf{F}$} & \multirow{2}{*}{ Significance } & \multirow{2}{*}{$\mathbf{t}$} & \multirow{2}{*}{$\begin{array}{l}\text { degree of } \\
\text { freedom }\end{array}$} & \multirow{2}{*}{$\begin{array}{c}\text { Sig. } \\
\text { (2-tailed) }\end{array}$} & \multirow{2}{*}{$\begin{array}{c}\text { Mean } \\
\text { difference }\end{array}$} & \multirow{2}{*}{$\begin{array}{l}\text { Standard } \\
\text { error } \\
\text { difference }\end{array}$} & \multicolumn{2}{|c|}{$\begin{array}{c}\text { 95\% Confidence } \\
\text { interval }\end{array}$} \\
\hline & & & & & & & & & $\begin{array}{l}\text { Lower } \\
\text { limit }\end{array}$ & $\begin{array}{l}\text { Upper } \\
\text { limit }\end{array}$ \\
\hline \multirow{2}{*}{$\begin{array}{l}\text { Academic } \\
\text { situation }\end{array}$} & $\begin{array}{c}\text { Equal Variance } \\
\text { Assumed }\end{array}$ & 1.645 & 0.202 & 1.844 & 159 & 0.067 & 0.243 & 0.13187 & -0.017 & 0.50356 \\
\hline & $\begin{array}{c}\text { Equal Variance } \\
\text { Not Assumed }\end{array}$ & & & 1.913 & 131.745 & 0.058 & 0.243 & 0.12707 & -0.008 & 0.49447 \\
\hline \multirow{2}{*}{$\begin{array}{l}\text { Interpersonal } \\
\text { relationship }\end{array}$} & $\begin{array}{c}\text { Equal Variance } \\
\text { Assumed }\end{array}$ & 3.66 & 0.058 & 1.846 & 159 & 0.067 & 0.284 & 0.15406 & -0.02 & 0.58864 \\
\hline & $\begin{array}{c}\text { Equal Variance } \\
\text { Not Assumed }\end{array}$ & & & 1.911 & 130.863 & 0.058 & 0.284 & 0.14881 & -0.01 & 0.57875 \\
\hline \multirow{2}{*}{$\begin{array}{l}\text { Environmental } \\
\text { factors }\end{array}$} & $\begin{array}{c}\text { Equal Variance } \\
\text { Assumed }\end{array}$ & 3.375 & 0.068 & 2.4 & 159 & 0.018 & 0.264 & 0.11014 & 0.0468 & 0.48184 \\
\hline & $\begin{array}{c}\text { Equal Variance } \\
\text { Not Assumed }\end{array}$ & & & 2.235 & 95.773 & 0.028 & 0.264 & 0.11824 & 0.0296 & 0.49902 \\
\hline \multirow{2}{*}{$\begin{array}{l}\text { Psychological } \\
\text { adaptation }\end{array}$} & $\begin{array}{c}\text { Equal Variance } \\
\text { Assumed }\end{array}$ & 5.876 & 0.016 & -2.719 & 159 & 0.007 & -0.35 & 0.12928 & -0.607 & -0.09618 \\
\hline & $\begin{array}{c}\text { Equal Variance } \\
\text { Not Assumed }\end{array}$ & & & -2.55 & 97.675 & 0.012 & -0.35 & 0.13785 & -0.625 & -0.07793 \\
\hline \multirow{2}{*}{ Total score } & $\begin{array}{c}\text { Equal Variance } \\
\text { Assumed }\end{array}$ & 4.232 & 0.041 & 1.239 & 159 & 0.217 & 3.197 & 2.58063 & -1.9 & 8.29342 \\
\hline & $\begin{array}{c}\text { Equal Variance } \\
\text { Not Assumed }\end{array}$ & & & 1.191 & 105.117 & 0.236 & 3.197 & 2.68432 & -2.126 & 8.51912 \\
\hline
\end{tabular}

${ }^{*} p \leq 0.05,{ }^{* *} p \leq 0.01,{ }^{* * *} p \leq 0.001$. 
and "environmental factors" are higher than the students in the medium academic level group, and there is a significant difference $(p \leq 0.05)$; the score of students in the high level academic group score is lower than that of the students in the medium academic level group on the "mental adaptation" dimension, and there is a significant difference $(p \leq 0.05)$.

The scores of students in the high academic level group on interpersonal relations and environmental factors are higher than those of students in the medium academic level group, and there is a significant difference $(p<0.05)$. The author believes that this is because students in the high academic group have better language skills than students in the medium academic group. Therefore, they can get more score in questions about measuring interpersonal relationships such as "make new friends in the UK", "participate in local social activities", "communication smoothly with the staff of the school dormitory or financial management department" and questions about measuring environmental factors such as "when I am going to travel to other places in the UK, I Can handle transportation and accommodation problems well", "When it is needed, I know how to seek help from a doctor or the police". This also gets confirmation in the subsequent case interviews. Some students mentioned that because they speak English well, they can communicate with local British people more confidently and integrate into their daily life more quickly after arriving in the UK.

The study also found that the psychological adaptation scores of students in the high academic level group are lower than those in the medium academic level group, that is, there is a negative correlation between these two, and there are significant differences. The author conducted a two-year follow-up study with 17 students through case interviews. Some students talked about the relationship between psychological adaptation and academic ability. According to the analysis of the researcher, the academic requirements of universities selected by the students in the high academic level group are strict. The instructor distributes a lot of reading materials and requires reading after class. The students are under great academic pressure every day. On the other hand, these students also have higher self-requirements for themselves. Some students in the high academic level group hope to get a first-class degree when they graduate, so that they can apply for a master's degree at the top universities in the UK. Therefore, strict school requirements and higher self-personal pursuits put students under greater psychological pressure ( $\mathrm{Ma}, 2016)$. The experimental results also verify the above statement.

However, there is no significant difference in the scores of students in the high academic level group and the medium academic level group in the dimension of "academic situation". This result is unexpected. However, after analyzing the case, it is found to be so. High-level British universities have extremely strict requirements on students, students are under great academic pressure, teachers provide more difficult knowledge, there are more extracurricular reading materials, and it is difficult for students to get high scores. On the other hand, me- 
dium-level British university students are relatively less stressed and students will be more likely to get satisfactory scores. Therefore, in the questions such as "writing a good grade essay", "reading and understanding the materials recommended by the tutor", and "habitually completing group tasks with foreign students", the score gap between two groups is not obvious.

The researchers analyzed that there are two possibilities. First, the quality of academic performance can only reflect the ability of Chinese students to master the content they have learned in Chinese universities. However, due to the differences in the educational models of Chinese and British universities, most Chinese students rarely have access to the British educational model when they are in China. Therefore, after Chinese students of different academic levels come to the UK to study, they will adapt to the British university education model at the same starting level. In other words, there is no interactive relationship between the level of mastery of Chinese university learning content and the level of adaptation to the British university education model (Sun, 2009). The mastery of learning content in Chinese university cannot be transferred to the task of adapting to the British university education model. Second, this experiment grouped different British universities, but different British universities have different teaching requirements for students, which may have effects on the results. In the next study, we will try to eliminate the influence of interference variables and study the cross-cultural adaptability of Chinese students with different academic levels in the same British university in order to obtain more accurate results.

\section{Conclusion}

In the past, it was generally believed that after students with better academic performance go to study in the UK, they would be more likely to achieve crosscultural adaptation due to their strong language skills and self-management skills (Liu, 2005). Through this research, we found that in the two dimensions of interpersonal relationships and environmental factors, students with good academic performance are indeed more likely to achieve cross-cultural adaptation. However, in the dimension of phycological adaption, students with good academic performance are not more likely to complete academic cross-cultural adaptation than students with weak academic performance. Students with good academic performance have more difficulties in psychological adaptation than students with weak academic performance in the dimension of psychological adaptation in cross-cultural adaptation. This study believes that there is no significant correlation between Chinese students of different academic levels and their level of cross-cultural adaptation after they arrive in the UK, but there are statistical correlations and significant differences in some specific dimensions. This research reveals that, first, academic level and cross-cultural adaptation are two independent factors. The academic level can only represent the degree of knowledge that Chinese students have when they study in China, but cannot reflect 
the ability of Chinese students to adapt to cross-culturally after studying in the UK. Second, students with strong English proficiency will be more likely to make new friends when studying in the UK, helping them to establish a new local interpersonal network as soon as possible, and also easily adapt to local social order and social norms. Third, there is no significant correlation between crosscultural adaptation and academic level. Cross-cultural adaptation should be used as a separate teaching unit to systematically train students who are going to study in the UK to help them achieve cross-cultural adaptation more easily.

\section{Funding}

This research is funded by the 2020 school-level scientific research project of Guangdong University of Foreign Studies "Research on Innovation of Disciplinary Construction Mechanisms in Foreign Language Colleges under the Background of New Liberal Arts" (project number: 20QN18). It is also a research report of Young Innovative Talent Cultivation Project in 2016 "Research on the Cultural Adaptability of the Trainees of the Articulation Program of Guangdong University of Foreign Studies from the Perspective of the Belt and Road Initiative" by Center for Foreign Literature and Culture of Guangdong University of Foreign Studies (project number: 16QNCX09).

\section{Conflicts of Interest}

The authors declare no conflicts of interest regarding the publication of this paper.

\section{References}

Fang, Y. Y. (2010). An Empirical Study on the Status Quo, Influencing Factors and Strategies of International Students' Cultural Adaptation. Journal of Inner Mongolia Normal University (Education Science Edition), 23, 39-42.

Huang, X. X. (1994). Discussion on the Adaptability of Contemporary Chinese Student Groups. Educational Research, No. 11, 42-46.

Jiang, H. S., Zhang, C. H., Xie, R. Y. et al. (2000). Studying Abroad at One's Own Expense and the Development Trend of Younger Age. Educational Development Research, No. 2, 35-40.

Li, X. Z. (2011). An Analysis of Overseas Chinese Students Cultural and Solution-A Case Study on Oklahoma State University. Chongqing: Chongqing University.

Liu, X. Q. (2005). The History of Modern Chinese Education in Britain (p. 252). Tianjin: Nankai University Press.

Ma, D. (2016). Research on the Influence Mechanism of Cultural Intelligence on CrossCultural Adaptation-Based on the Perspective of Cross-Cultural Psychological Adaptation. Theory and Reform, No. 3, 163-168.

Sun, G. L., \& He, G. S. (2009). The Causes and Countermeasures of Chinese Students' Maladjustment to Culture. China Extra-School Education, No. S2, 176-277.

Tan, Y. (2013). Research on the Cross-Cultural Adaptation of Students in Sino-Foreign Cooperation in Running Schools in Universities. Beijing: Central University for Nationalities. 
Tan, Y. (2014). On Self-Concept and Cultural Identity Reconstruction Issues of Chinese International Students. Contemporary Education and Culture, 6, 78-83.

Wang, K. C. (2013a). The Condition of Inter-Cultural Adaption in UK among the Chinese Postgraduate Students. Guilin: Guangxi University Press.

Wang, L. (2013b). Investigation of Chinese Young Abroad Students on Cross-Cultural Adaption-A Case Study of Chinese Young Abroad Students in America from Xintong Education Agent. Hefei: Anhui University Press.

Wang, Y. (2012). An Analysis of Chinese Students Studying Abroad in the United States and Their Cultural Adaptability. Anhui Literature, No. 7, 148-150.

Yang, L., Fu, N., Wang, M. N. et al. (2019). Influencing Factors of Chinese Students' Social-Cultural Adaption. Journal of Educational Studies, 15, 93-101.

Zhan, Z. (2017). China’s Self-Funded Study Abroad Behavior Research: From Perspective of Educational Consumption. Wuhan: Central China Normal University. 